\title{
UMA REVISÃO BIBLIOGRÁFICA SOBRE OS MODELOS DE NEGÓCIOS INOVADORES
}

\section{RESUMO}

O estudo busca solucionar questões relacionadas aos desafios gerados em uma sociedade baseada no conhecimento, que apresenta contextos de alta competição e cobra pontualidade e maturidade, no que se refere a abordagem, pelos diversos atores envolvidos no processo de inovação. Neste sentido, os modelos de negócios surgem como instrumentos capazes de criar valor e mudar contextos a partir de suas abordagens diferenciadas. Para tanto, faz-se necessário entender o contexto desta nova sociedade baseada no conhecimento, conhecendo alguns conceitos e perspectivas. Cabe entender também, o que a literatura fala sobre os modelos de negócios inovadores, que se colocam como objeto de estudo desta pesquisa. A pesquisa utiliza-se de uma abordagem qualitativa e fez uso do estudo bibliográfico como formas de coleta e análise de dados. Aos resultados, cabe ressaltar as contribuições geradas a partir das visões da literatura que contribuem para o fortalecimento dos modelos de negócios como instrumentos inovadores e com papel fundamental dentro de cenários que exigem pontualidade e muita atenção para com o contexto.

Palavras-chave: Modelos de Negócio; Criação de Valor; Sociedade Baseada no Conhecimento.

\section{A BIBLIOGRAPHIC REVIEW ON INNOVATIVE BUSINESS MODELS}

\begin{abstract}
The study seeks to solve issues related to the challenges generated in a knowledge-based society, which presents contexts of high competition and demands punctuality and maturity, as far as the approach is concerned by several actors involved in the innovation process. In this regard, business models emerge as instruments capable of creating value and changing contexts from their differential approaches. Therefore, it is necessary to understand the context of this new society based on knowledge, understanding some concepts and perspectives. It is also possible to understand what the literature talks about innovative business models, which stands as study of this research. The research reports a qualitative approach and the bibliographic study as ways of data collection and analysis. About the results, it is worth highlighting the contributions generated from the visions of the literature that contribute to the strengthening of business models as innovative instruments and with a fundamental role in scenarios that require punctuality and a lot of attention to the context.
\end{abstract}

Keywords: Business Models; Value Creation; Knowledge-Based Society. 


\section{UNA REVISIÓN BIBLIOGRÁFICA SOBRE LOS MODELOS DE NEGOCIOS INNOVADORES}

\section{RESUMEN}

El estudio busca solucionar cuestiones relacionadas con los desafíos generados en una sociedade basada en el conocimiento, que presenta contextos de alta competición y cobra puntualidad y madurez, en lo que se refiere al abordaje, por los diversos actores involucrados en el proceso de la innovación. En este sentido, los modelos de negocios surgen como instrumentos capaces de crear valor y cambiar contextos a partir de sus enfoques diferenciados. Para ello, se hace necesario entender el contexto de esta nueva sociedad basada en el conocimiento, conociendo algunos conceptos y perspectivas. Cabe entender también, lo que la literatura habla sobre los modelos de negocios innovadores, que se plantean como objeto de estudio de esta investigación. La la investigación se utiliza de un abordaje cualitativo e hizo uso del estudio bibliográfico como formas de recolección y análisis de datos. A los resultados, cabe resaltar las contribuciones generadas a desde las visiones de la literatura que contribuyen al fortalecimiento de los modelos de negócios como instrumentos innovadores y con un papel fundamental dentro de escenarios que puntualidad y mucha atención hacia el contexto.

Palabras clave: Modelos de Negocio; Creación de Valor; Sociedad Basada en el Conocimiento.

Yuri Borba Vefago ${ }^{1}$ Thiago Henrique Almino Francisco ${ }^{2}$ Marina Keiko Nakayama ${ }^{3}$

\footnotetext{
${ }^{1}$ Mestrando pelo Programa de Pós-Graduação em Tecnologias da Informação e Comunicação da Universidade Federal de Santa Catarina - PPGTIC/UFSC. Brasil. E-mail: yurivefago@gmail.com

${ }^{2}$ Doutor pelo Programa de Pós-Graduação em Engenharia e Gestão do Conhecimento da Universidade Federal de Santa Catarina - EGC/UFSC. Professor da Universidade do Extremo Sul Catarinense - UNESC. Brasil. E-mail: tfrancisco@unesc.net

3 Doutora em Administração pela Universidade Federal do Rio Grande do Sul - UFRGS. Professora do Centro Universitário de Brusque - UNIFEBE e do Departamento de Engenharia do Conhecimento da Universidade Federal de Santa Catarina - EGC/UFSC. Brasil. E-mail: marina@egc.ufsc.br
} 


\section{INTRODUÇÃ̃O}

Na sociedade do conhecimento, a manutenção de uma proposição de valor pelas organizações transcorre em meio ao equilibrado processo de inovação. As demandas da sociedade emergem de contextos em que o capital intelectual assume papel de destaque, o que colabora para o acréscimo de complexidade e influencia o modus operante das organizações, que precisam se adequar as grandes e rápidas transformações impostas pelo mercado.

Sob esta ótica, a gestão eficiente do capital intelectual passa a ser essencial e em diversos cenários pré-requisito para entrada em dados mercados. Gerar vantagem competitiva tornou-se cada vez mais difícil e desafiador para as organizações, que precisam adequar suas proposições de valor a necessidades cada vez mais complexas. Takeuchi e Nonaka (2008) destacam a ocorrência das mudanças em múltiplas dimensões, o que coloca a gestão do conhecimento no centro das atenções do que a gestão precisa fazer para vencer os novos desafios impostos pelo mercado

Sob este pano de fundo se inserem os modelos de negócios, instrumentos cuja função principal é ajudar os gestores e todos os atores envolvidos no processo de inovação a navegarem com maior clareza nesse mundo mais conectado. Os modelos de negócios trabalham para deixar de forma mais clara e didática as informações relevantes para construção de valor pelas organizações, o que colabora para que todos os envolvidos ajam pelos mesmos princípios e tornem o trabalho mais facilitado e efetivo.

Portanto, conhecer e entender o que a literatura fala sobre os modelos de negócios inovadores se faz essencial no contexto da sociedade baseada no conhecimento. Neste sentido, este estudo busca, a partir das contribuições apresentadas pela literatura, desmistificar estes conceitos e contribuir para o enriquecimento da literatura a partir de uma abordagem diferenciada de estudo.

No sentido de apresentar as contribuições deste artigo, a pesquisa foi estruturada em cinco seções. A primeira seção, introdutória, busca elucidar os principais assuntos a serem abordados nesta pesquisa. $\mathrm{Na}$ segunda, a fundamentação teórica, que dá sustentação para todo estudo a partir do acréscimo dos principais conceitos diretamente ligado com o objeto de estudo. Por terceiro, os procedimentos metodológicos, que representam todo o planejamento previamente executado para o desenvolvimento eficiente e coeso desta pesquisa, dando ênfase na utilização da revisão integrativa. Na quarta seção são apresentados os resultados deste artigo, com a contribuição gerada a partir da literatura. Na quinta seção são apresentadas as considerações finais, contendo as percepções geradas a partir dos resultados ao final da pesquisa.

\section{CONTRIBUIÇÕES TEÓRICAS}

\subsection{A Gestão do Conhecimento Organizacional}

A Gestão do Conhecimento Organizacional representa um momento divisor de águas, a passagem de uma era industrial para a era do conhecimento. Trata-se do encerramento de um ciclo com uma atenção fortemente linear, para a maximização de um novo ciclo maior e mais complexo. Os fatores responsáveis por esta passagem são diversos, como mudanças demográficas, a escassez de recursos, a globalização da economia, o desenvolvimento tecnológico e o conhecimento. Takeuchi e Nonaka (2008) chamam este momento de "elevação do paradoxo", a passagem de uma sociedade industrial para uma sociedade do conhecimento, uma sociedade que propõe um novo desafio, complexo e que passa pela gestão equilibrada destes e de outros fatores que são responsáveis pela consecução de vantagens competitivas sustentáveis por parte das organizações.

As contribuições de Trierveiler (2015) se encaixam com o que é exposto por Takeuchi e Nonaka (2008) ao destacar que a gestão do conhecimento pode ser entendida como o processo de tornar o conhecimento horizontal, tornando-o acessível para quaisquer atores que estejam envolvidos direta e indiretamente com o processo de inovação. $O$ que chama atenção para uma questão muito salutar, que se relaciona com os quesitos de entrada desta nova sociedade do conhecimento. Tais quesitos colocam em evidencia o capital intelectual e são representados pelo fomento da educação, da rede e da cooperação, subentendendo-se desta forma, que estes são requisitos fundamentais para a manutenção de uma trajetória equilibrada e com status positivo.

Davenport e Prusak (1998) destacam que além de tornar o conhecimento usual, um dos grandes desafios dessa nova sociedade do conhecimento é saber usufruir de toda a informação disponível. Existe uma quantidade de informação quase que incalculável de informação e saber escolher entre o que é relevante e o que não é ou como aplicar um conhecimento adquirido é essencial durante o processo. Tal desafio perpassa principalmente pelos níveis estratégicos das organizações, o que reforça o papel da gestão do conhecimento dentro das organizações, que não devem significar somente um incremento tecnológico ou a criação de um setor dentro da organização, mas devem estar intrínsecos na tomada de cada decisão por parte dos atores responsáveis pela geração de uma vantagem competitiva dentro da organização.

As visões de Davenport e Prusak (1998) complementam as ideias apresentadas por Drucker (1999), que ressalta o papel do trabalhador do conhecimento dentro da economia do conhecimento. Torna-se fundamental, neste âmbito, trabalhar com uma equipe equilibrada e que contemple em todos os 
níveis, pessoas habituadas aos novos desafios desta economia conectada, que estejam abertas e preparadas para as constantes mudanças inerentes ao processo de inovação, mudanças que cobrarão muita resiliência e capacidade de resolução de problemas por parte destes atores.

As contribuições de Tschumi (2015) colaboram com as visões de Drucker (1999) e vai mais além, ao chamar a atenção para o papel do cliente dentro do processo de inovação, ator que possui lugar de destaque na nova economia do conhecimento. É perceptível a esta altura notar o aumento da complexidade no que se refere ao gerenciamento da operação para a criação de um produto/serviço, existe neste momento a associação com os pilares citados por Takeuchi e Nonaka (2008), que ditam o ritmo e devem estar presentes em toda a análise envolvida na concepção de um novo produto/serviço, o que pode colaborar para o sucesso ou não em um dado mercado.

Portanto, a visão da literatura sobre a gestão do conhecimento destaca a transição para uma economia baseada no conhecimento, em que o capital intelectual entra em evidencia e passa a desempenhar um papel fundamental na criação de valor para as organizações e, sob esta marca, são apresentados alguns fatores responsáveis por esta transição, que se afunilam com a globalização como pano de fundo e epicentro desta nova sociedade. Neste sentido, o trabalhador do conhecimento assume papel de destaque, tornando-se peça chave para o processo de inovação e a sua evolução deve caminhar junto com as mudanças e pelos desafios colocados pela nova economia do conhecimento. Como gerir os diversos atores e os diversos conhecimentos passa a ser o grande desafio das organizações.

\subsection{Os Conceitos de Inovação e a Importância do Processo de Gestão da Inovação para a Criação de Valor nas Organizações}

O gerenciamento estratégico da inovação tornou-se tema central na investigação de muitos estudiosos, é possível verificar a existência de muitos materiais relacionados ao tema, mas que apresentam uma fundamentação rasa e pouco significativa para a utilização por gestores organizacionais. $\mathrm{O}$ tema assume formas complexas em certos momentos, o que dificulta a sua utilização mais direta e efetiva e pouco ajuda gestores no fomento de insights e é latente a necessidade de simplificação e de criação de materiais mais significativos (Keupp, Gassmann, 2012). As margens da nova sociedade do conhecimento, a inovação desempenha papel central em todo o processo de manutenção de uma vantagem competitiva e sua correta compreensão se faz necessária por parte dos diversos atores envolvidos em seu ganho. Vantagem competitiva é inovação ou vice-versa, um não existe sem o outro e a manutenção de uma vantagem competitiva é o grande carro chefe dos modelos de negócio. Portanto, entender os principais conceitos de inovação e gestão da inovação são os principais objetivos desta seção, bem como entender a relação virtuosa destes conceitos com os modelos de negócio (Palombo, 2006).

Tidd e Bressant (2015) enxergam a inovação como fator dominador na consecução de vantagem competitiva. Anteriormente atrelado ao patrimônio, a vantagem competitiva requer hoje, mais engajamento e uma abordagem diferenciada, requer um melhor aproveitamento dos diferentes atores que participam direta e indiretamente do processo de inovação. O novo cenário corporativo cobra das organizações mais atenção para com as necessidades dos clientes e sobretudo cobra soluções mais rápidas e eficientes.

Sob a ótica de Davila, Epstein e Shelton (2009) a inovação apresenta características diferentes dependendo do contexto em que é inserida e é salutar compreender que praticá-la em demasia e não alinhada com os requisitos da organização pode se tornar um fato negativo. A inovação precisa estar adequada com competências e possibilidades da organização ou pode contribuir negativamente e alterar o foco principal da empresa.

O Manual de Oslo (1997) ressalta o papel da inovação dentro do contexto organizacional e acrescenta que as inovações podem surgir de muitas necessidades. Entre elas, pode-se citar a mudança de característica de um produto, o incremento de uma melhoria ou uma nova função, a criação de um novo produto ou a implementação de um novo processo. A natureza da inovação é singular e pode advir do mais improvável centro organizacional, o que reforça o papel transformador desempenhado por cada colaborador dentro da organização.

Tidd e Bressant (2015) chamam atenção para os objetivos da inovação em algumas organizações. Eles afirmam que muitas organizações se prendem a inovação como salvação de suas empresas em momentos de instabilidade, o que prejudica o processo e pode produzir um resultado negativo para empresa. A inovação enquanto pano de fundo deve estar intrínseca na cultura da organização, deve coexistir de forma clara para todos os atores envolvidos, o que contribui para a produção equilibrada e de forma contínua de inovações pela organização.

$\mathrm{O}$ gerenciamento da inovação torna-se fundamental neste cenário. Dorow (2013) destaca que a gestão efetiva da organização contribui para a minimização das imperfeições produzidas (normais) durante o processo de inovação e com a maximização das potencialidades da empresa. $\mathrm{O}$ "gestor da inovação" precisa ter atenção para com as oportunidades externas e internas, a menor das oportunidades pode produzir resultados significativos se verificada de forma pontual e bem gerenciada.

A adoção da postura inovadora por uma organização exige mudanças significativas no modelo de negócio da empresa, as frentes política e estratégica 
entregam neste momento o plano a longo prazo para a empresa. Este momento assume papel decisivo em muitas empresas, pois define o caminho a ser trilhado e sobretudo definirá quem a empresa vai ser. O que evidencia o papel da gestão da inovação nos momentos importantes da vida da empresa, o que demanda equilíbrio e versatilidade por parte principalmente dos níveis táticos. (Coelho, 2013).

Ao final desta seção e a partir das contribuições de Matias-Pereira e Kruglianskas (2005), percebe-se que a inovação e a gestão da inovação andam juntas. A inovação, a margem desta nova economia baseada no conhecimento assume papel fundamental e passa a ser pilar central de grandes discussões em torno da consecução de resultados melhores para as organizações. A gestão da inovação, por outro lado, destaca-se como ferramenta indispensável e torna-se responsável por canalizar e fomentar toda e qualquer inovação dentro das organizações e na sociedade.

\subsection{A Importância da Tríplice Hélice Dentro no Ambiente Inovativo}

Ligado a importância dos diversos atores dentro do processo de inovação, discute-se a importância de abordagens que acelerem e produzam um resultado significativo. Sob esta ótica, surge o conceito da tríplice hélice. Este conceito traduz a interação de três pilares fundamentais para a inovação: a universidade, as empresas e o governo. Etzkowitz e Leydesdorff (2000) afirmam que a interação efetiva destas três esferas produz um resultado positivo para o processo de inovação. Costa (2010) destaca que existem três estágios que compõem o modelo da tríplice hélice, a definição dos papéis institucionais e transferências de tecnologias, o surgimento de novas formas de comunicação e interação com o mercado para a transferência de e a apropriação dos papeis uns dos outros dentro do processo de inovação.

Sob a ótica de Vaccaro e Mendes (2011), este modelo traz consigo uma abordagem diferente por parte das três esferas. A universidade assume um papel extensionista, utilizando o seu capital intelectual para resolução de problemas recorrentes e exercendo o papel de articulador. O governo, trabalhando para a otimização e desburocratização (por vezes se apegando a modelos globais, o que desmistifica muitos paradigmas ligados a máquina pública) e, por último, as organizações, com uma perspectiva menos "capitalista" ou voltada para o puro lucro e uma abordagem voltada para criação de valor também, para sociedade.

\subsection{Os Modelos de Negócios Inovadores: Um Resultado do Processo de Inovação}

Os modelos de negócios estão ligados diretamente com o processo de inovação, com 0 processo de gestão da inovação e sobretudo com este novo cenário corporativo de alta competição imposto pela sociedade do conhecimento. Segundo Osterwalder e Pigneur (2011), os modelos de negócios geram um resultado rápido e eficiente dentro de cenários competitivos. Os modelos de negócios, relacionam-se com método, com criação de valor, com facilitação, eles são capazes de gerar resultados significativos muito facilmente e são extremamente adaptáveis. Está ligado a concepção e manutenção de negócios, tendo um papel de organizador.

Os modelos de negócios apresentam como uma de suas características principais a clareza na comunicação de seus objetivos, variáveis que se tornam decisivas dentro do contexto organizacional. A ferramenta consegue de forma facilitada explanar os principais objetivos e valores relacionados a proposta da organização, o que contribui para o alinhamento mais efetivo de todos os atores envolvidos no processo de inovação e produz melhores resultados ao final do processo. (Magretta, 2002).

Segundo Soto (2014), o termo modelo de negócios tomou uma proporção maior a partir dos anos 90, com o advento da internet e com a experimentação de um mundo mais conectado, as organizações foram forçadas a rever seus modelos e suas estratégias para manter a competitividade. A busca acerca dos modelos de negócio é marcada por diferentes momentos, a saber:

- Concepção;

- Criação de conceitos e classificação dos modelos de negócio;

- Complementação e acréscimo com novas proposições;

- Combinação de conceitos e sugestão de modelos;

- Aplicação destes modelos.

De acordo com Tidd e Bressant (2015), a inovação está ligada com a identificação de oportunidades. $\mathrm{Na}$ sociedade do conhecimento, a informação tem seu acesso mais facilitado, o que aumentou a competição para níveis jamais vistos, fatores que colaboram para a criação de um ambiente mais instável e de muita competição. Dentro desta perspectiva, os modelos negócio se encaixam e suprem uma necessidade muito importante requerida pelas organizações e anteriormente não satisfeita: a fácil organização do que é importante para a empresa e o escopo de projeções gerados a partir da ferramenta.

Nas perspectivas de Osterwalder e Pigneur (2011), inovar em modelos de negócios não é algo fácil, é quebrar paradigmas e superar modelos antigos, está ligado diretamente à cultura organizacional, o que confirma o que foi exposto por Tidd e Bressant (2015) acerca da cultura organizacional. Inovar não é algo simples, organizações que querer se tornar inovadoras dever modificar seus modelos e ressaltar a importância 
dos diversos atores envolvidos no processo de inovação dando espaço e oportunidades para que estas pessoas possam desenvolver o seu pleno potencial.

No entendimento de Karam (2006), um modelo de negócio expressa a ideia principal de um negócio, são as principais variáveis que realmente importam e fazem o negócio acontecer. A forma e a disposição dos epicentros de inovação colaboram para uma leitura rápida e efetiva da proposta de valor da organização, o que colabora para uma tomada de decisão mais clara e facilitada, de modo a minimizar os erros durante a concepção de uma proposta de valor.

A partir das contribuições da literatura é possível perceber a complexidade atrelada ao processo de inovação, apresentando desafios maiores para a aquisição de vantagens competitivas sustentáveis. Os modelos de negócios se inserem nesse contexto como uma alternativa para a simplificação deste processo e para a canalização mais rápida dos resultados, o que caminha na mesma direção trilhada pela sociedade do conhecimento.

\section{PROCEDIMENTOS METODOLÓGICOS}

Com relação aos aspectos metodológicos, cabe aqui ressaltar a abordagem empregada na execução da pesquisa e os meios utilizados para seu desenvolvimento. A pesquisa caracterizou-se como qualitativa e de cunho bibliográfico. Segundo Godoy (1995, p. 6) a pesquisa de ordem qualitativa "têm como preocupação fundamental o estudo e a análise do mundo empírico em seu ambiente natural", sendo muito valorizado o prolongamento da interação mais direta entre pesquisador e objeto estudado. Quanto a pesquisa bibliográfica, segundo Gil (2002, p.44), tratase de uma pesquisa "desenvolvida com base em material já elaborado, constituído principalmente de livros e artigos científicos", ou seja, fontes já consolidadas, o que permite ao pesquisador um maior compreendimento acerca dos fenômenos estudados e colabora com a efetividade dos resultados da pesquisa.

\section{A CARACTERIZAÇÃo do PROCESSO DE CONSTRUÇÃO DE MODELOS DE NEGÓCIO: UMA VISÃO A PARTIR DA LITERATURA}

Nas seções que seguem serão apresentados os resultados acerca do objeto de estudo a partir da análise dos trabalhos pesquisados.

É consenso que o objeto de estudo pesquisado ainda é insipiente e não existe uma máxima acerca do tema, logo, apoiar-se na literatura torna-se fundamental para formação de uma base solida. A partir do levantamento de questionamentos, monta-se então um planejamento pautado em alguns pilares essenciais que centram-se na caracterização dos trabalhos pesquisados e na construção de uma percepção a partir da revisão sistemática realizada a partir das visões dos diversos entendedores acerca do objeto de estudo.

Portanto, a partir dos questionamentos levantados, na seção que segue será realizada a caracterização dos trabalhos pesquisados.

\subsection{A Caracterização dos Trabalhos Pesquisados: Uma Visão Geral dos Estudos Acerca dos Modelos de Negócios Inovadores}

Esta seção busca caracterizar os estudos pesquisados e utilizados neste artigo a fim de dar mais transparência e explanar como foi conduzido a pesquisa. O processo foi dividido em dois momentos: a seleção dos trabalhos e a síntese das principais contribuições apresentadas pelos artigos.

A busca foi conduzida nas bases da Spell (todas as bases), Doaj (todas as bases), Anpad (todas as bases) e Scopus (todas as bases).

\begin{tabular}{|c|c|}
\hline CRITÉRIOS DE BUSCA & CRITÉRIOS DE INCLUSÃO \\
\hline "Inovação AND Modelo de Negócio" em português & Ambos os termos no título e/ou no resumo \\
\hline "Ideação AND Inovação" em português & Artigos \\
\hline "Ideação AND Modelo de Negócio" em português & $\begin{array}{c}\text { Trabalhos que apresentem qualquer um dos termos } \\
\text { que sejam interessantes e que abordem um dos } \\
\text { termos da pesquisa serão eventualmente utilizados }\end{array}$ \\
\hline
\end{tabular}

Quadro 2 - Critérios para condução da pesquisa Fonte: Elaborado pelo autor.

O número de trabalhos analisados representou um total de 14 artigos, sendo 12 oriundos do banco do portal DOAJ e 2 oriundos do portal da SPELL. Durante o levantamento o autor procurou seguir à risca os critérios de busca e neste sentido, sugere-se em trabalhos futuros a redefinição dos critérios de busca para um melhor aproveitamento dos bancos de artigos.

\subsection{O estudo dos modelos de negócio}

Sendo os modelos de negócio o objeto de estudo desta pesquisa, a sua caracterização se faz essencial. A seção que segue busca apoiar-se na literatura para verificar o que a literatura diz sobre os modelos de negócios inovadores. 


\subsubsection{As contribuições da literatura empírica sobre modelos de negócio inovadores}

O modelo de negócio tem como virtude principal a descrição lógica dos caminhos para a criação de valor por uma empresa. Araujo e Zilber (2013) destacam a dificuldade na execução desta tarefa como um dos principais problemas dos modelos de negócios da atualidade, que contam com gestões centralizadas e que encontram dificuldades para disseminar com clareza os principais objetivos da organização. A falta de conhecimento e de compreensão dos objetivos organizacionais impacta diretamente na consecução da vantagem competitiva e precisa ser compor uma das primeiras atividades da gestão organizacional, em vias de construir uma equipe alinhada com os principais valores da organização.

De acordo com de Araujo, Oliveira, Cazarini e Oliveira (2013) o processo de inovação organizacional, bem como a adoção de um modelo de negócio competitivo depende indiretamente do planejamento estratégico firmado pela entidade. $O$ processo é marcado pela quebra de paradigmas, pela experimentação e construção de novas competências, pelo bom recebimento por parte de toda a equipe de atores envolvidos no processo e pelo alto investimento tecnológico e em recursos midiáticos. Existe a necessidade de grande envolvimento por toda a equipe de atores envolvidos na construção do valor organizacional, dando sentido a todo o investimento e planejamento dispendido pela organização, que sem tal postura transforma-se em prejuízo e pouco contribui para o aumento de competitividade.

As contribuições de Flores (2017) complementam de Araujo, Oliveira, Cazarini e Oliveira (2013) ao dar ênfase no trabalho em equipe como fator fundamental para o processo de inovação. $O$ autor chama a atenção para o papel do consumidor final dentro da nova sociedade do conhecimento, as organizações precisam atentar-se para compreensão dos comportamentos, hábitos, gostos e necessidades deste indivíduo, que é responsável pelo aumento de complexidade na construção dos modelos de negócio inovadores.

Sob a ótica de Camargo Guerrazzi, Zanin e Falaster (2016), são fatores determinantes na construção de modelos de negócios inovadores a adoção da heterogeneidade em função da efetiva utilização dos recursos que se tema disposição. Existe a necessidade neste momento da máxima exploração, verificação e combinação destes recursos, que serão responsáveis pela aquisição de novas competências organizacionais, variáveis responsáveis pela aquisição de vantagem competitiva pela organização e principalmente pela sustentação do modelo de negócio. A aquisição de novas competências em modelos de negócios inovadores está ligada ao procedimento de acumulação de aprendizagem organizacional, exercício cada vez mais fundamental dentro da sociedade do conhecimento e que trabalha para a síntese do que é mais importante para a organização em dado momento.

As contribuições de Jacomossi e Demajorovic (2017) chamam novamente a atenção para a importância da aprendizagem organizacional em modelos de negócios inovadores, os autores destacam que a aprendizagem organizacional tem intervenção direta no sucesso do processo de inovação. Eles ainda destacam os papéis do líder empreendedor e das questões relacionadas a regulação, de um lado o líder organizacional precisa assumir o papel de líder empreendedor na nova sociedade do conhecimento para acompanhar as mudanças e as dificuldades que o mercado impõe. Este líder precisa, entre outras coisas, adquirir uma visão mais holística de toda organização e possuir características que lhe permitam maior adaptação e poder de decisão em momentos que o mercado lhe impõe. De outro a regulação coloca mais complexidade e torna mais desafiador o ambiente das empresas, que precisam cada vez mais se adaptar a rígidas questões legais/ambientais e a pontos de vistas e pressões populares colocados em dados mercados.

De acordo com Juliani, Sczymczak, do Amarante e de Guimarães (2015), a atuação do líder empreendedor tem papel fundamental no sucesso de um modelo de negócio inovador. Sob a ótica da sociedade do conhecimento, os líderes organizacionais precisam assumir papéis ativos dentro das empresas e demonstrar muita resiliência para com futuros insucessos em dadas investidas, a constante insistência na construção de uma organização de excelência se faz essencial neste momento.

A presença do empreendedorismo nos modelos de negócios inovadores se faz mais uma vez presente sob as perspectivas de Renault, Araujo Fonseca, Cunha e da Silva Carvalho (2011), que trazem contribuições que provem resquícios dos conceitos da Tríplice-Hélice (universidades-empresas-governo), ao ressaltarem o papel das incubadoras, dos escritórios de transferência de tecnologia e dos parques tecnológicos para a formação de empresas inovadoras. A atuação destas três instancias se faz fundamental na nova sociedade do conhecimento, onde grande parte das empresas encontram-se em estado frágil e precisam incessantemente de suporte técnico-qualificado para sua futura potencialização.

$\mathrm{O}$ conhecimento organizacional relacionado à inovação é colocado em evidencia sob as perspectivas de Trierveiler, Sell e Pacheco (2015), os autores dão ênfase nesta combinação e na utilização do conhecimento organizacional como insumo para o processo de inovação em modelos de negócios inovadores. É salutar destacar as evidencias que validam tal relação, que são potencializadas a partir da efetiva execução de alguns fatores, tais como: a perícia em torno do modelo de negócio em vigor, a aquisição de conhecimento a partir de tentativas e erros, conhecimentos presentes na organização a partir de experiências passadas, a clareza acerca das 
oportunidades oferecidas pelo mercado, a presença de um modelo de negócio flexível em função de oportunidades internas e externas e investimentos. Resultado deste processo é a aquisição de novos conhecimentos importantes para a consecução de vantagem competitiva, bem como a sobrevivência em mercados competitivos.

Turri e Abreu (2015) destacam o advento da internet como motor propulsor de uma série de mudanças que causaram impacto nos modelos de negócios das organizações. Os autores salientam o caráter imprevisível que a internet impõe para as organizações, especificamente as com modelos de negócio mais tradicionais e possuidores de propostas de valor mais rígidas. Esse mundo de possibilidades obriga estas organizações a trabalhar incessantemente em exercícios para modificar suas propostas a fim da obtenção de ganho de atratividade e manutenção de vantagens competitivas sustentáveis.

As contribuições de Bonazzi e Zilber (2014) avocam atenção para a relação teórica do funil de inovação (fuzzy front-end) com os modelos de negócios inovadores. É possível identificar a complementariedade dos conceitos, sendo representado por uma abordagem estática por parte dos modelos de negócio e com perspectivas dinâmicas e faseadas por parte do funil de inovação.

Rodrigues, Silveira, Kono e Lenzi (2013) dão ênfase na execução equilibrada de estratégias organizacionais no que concerne o sucesso dos modelos de negócios inovadores. Na sociedade do conhecimento é latente a necessidade da adequação da proposta de valor pela organização de forma definida e adequada as necessidades do público alvo em questão, o que colabora para diferenciação da empresa dentro do mercado a partir da oferta de uma proposta singular e adequada.

Portanto, a partir das contribuições da literatura é perceptível notar o ambiente de mudanças imposto pela nova sociedade do conhecimento, que tornou o processo de inovação mais complexo e desafiador. É salutar salientar a verificação do objetivo primordial da seção, que se mostrou validado a partir da constatação das características dos modelos de negócios inovadores e da consolidação desta ferramenta como "facilitadora" dentro de novos ambientes caóticos.

\section{CONSIDERAÇÕES FINAIS}

A sociedade do conhecimento cobra dos diversos atores envolvidos no processo de inovação uma abordagem diferenciada. O contexto é de extrema competição e permite o acesso facilitado a informação, o que potencializa os marcados tornando-os extremamente competitivos. Portanto, localizar-se neste contexto se faz essencial para a competitividade das organizações.
E entender o contexto, representa conhecer os insumos que se tem à disposição e saber como utilizados de maneira eficiente, atacando diretamente os problemas ou as oportunidades. Portanto, o entendimento por parte dos diversos atores acerca do seu papel dentro do contexto é fundamental para a geração de valor nestas organizações e para sociedade.

As contribuições geradas a partir da revisão bibliográfica da literatura propiciaram uma revisão sistemática e consistente, que aponta para a efetividade dos modelos de negócios, que utilizados dentro do contexto certo, podem contribuir de maneira significativa no ambiente inovativo.

Foi possível também, conhecer as principais pontos destacados pela literatura sobre os modelos de negócios inovadores e verificar uma série de carências existentes no ambiente inovativo brasileiro, promissor, mas carente de abordagens diferencias pelas diversas instancias envolvidas, fundamentalmente o governo, propiciando políticas favoráveis para a otimização do fluxo, a universidade, detentora do conhecimento, podendo incorporar qualidade ao processo e atuando como interlocutora e as empresas, que são as protagonistas do processo, capazes de girar este fluxo e gerar valor para a sociedade.

A partir da visão geral dos trabalhos sobre os modelos de negócio, pode-se concluir que estes instrumentos tornaram-se indispensáveis em uma nova sociedade baseada no conhecimento. São instrumentos que apresentam aderência e agilidade em ambientes de extrema competição que precisam de uma abordagem mais pontual e rápida. Sobretudo, os modelos de negócio representam uma nova forma de se pensar no negócio, os novos mercados via de regra não aceitam mais antigos paradigmas, estes novos mercados são amparados por conceitos inovadores e, desta forma, ao inovar, as empresas devem estar comprometidas em criar valor em suas ações.

Portanto, a partir dos estudos gerados, pode-se concluir que este novo ambiente, baseado no gerenciamento eficiente do conhecimento coloca-se como desafiador, mas propenso a muitas oportunidades para aqueles que souberem aproveitar. E, dentro desta reflexão, o contexto inovativo apresenta-se como deficitário, carente de uma nova abordagem facilitadora, que otimize o fluxo e gere valor mais rapidamente. Neste contexto, os modelos de negócio, surgem, com suas abordagens diferenciadas, capazes de elucidar e contribuir positivamente para a resolução de problemas/oportunidades geradas a partir deste ambiente caótico. 


\section{REFERÊNCIAS}

Araujo, J. B. D., \& Zilber, S. N. (2013). Adoção de EBusiness e mudanças no modelo de negócio: inovação organizacional em pequenas empresas dos setores de comércio e serviços. Gestão \& Produção, 20(1), 147-161.

Bonazzi, F. L. Z., \& Zilber, M. A. (2014). Inovação e modelo de negócio: Um estudo de caso sobre a integração do funil de inovação eo modelo canvas. Revista Brasileira de Gestão de Negócios, 16(53), 616-637.

Coelho, D. B. (2013). Franquias brasileiras: estratégia, empreendedorismo, inovação e internacionalização. Revista de Administração Contemporânea, 17(1), 126-130.

Costa, A. D. S. M. D. (2010). Convergências, divergências e silêncios: o discurso contemporâneo sobre o empreendedorismo nas empresas juniores e na mídia de negócios. Tese de Doutorado, Fundação Getúlio Vargas, Rio de Janeiro.

Davenport, Thomas H., \& Prusak, Laurence. Conhecimento empresarial: como as organizações gerenciam o seu capital intelectual. Rio de Janeiro: Campus.

Davila, T., Epstein, M. J., \& Shelton, R. (2009). As regras da inovação. Porto Alegre: Bookman.

de Araújo, E. M., de Oliveira Neto, J. D., Cazarini, E. W., \& Oliveira, S. R. M. (2013). A gestão da inovação na educação a distância. Gestão \& Produção, 20(3), 639-651.

de Camargo Guerrazzi, L. A., Zanin, L. M., \& Falaster, C. D. (2017). Você Diz Que Quer Uma Revolução: Todos Queremos Mudar o Mundo. Revista IberoAmericana de Estratégia, 16(1), 138.

Dorow, P. F. (2013). O processo de geração de ideais para inovação: estudo de caso em uma empresa naútica. Dissertação de Mestrado, Universidade Federal de Santa Catarina, Florianópolis.

Drucker, P. F. (1999). Desafios gerenciais para o século XXI. São Paulo: Pioneira.

Etzkowitz, H., \& Leydesdorff, L. (2000, February). The dynamics of innovation: from national systems and "mode 2" to a triple helix of universityindustrygovernment relations. Research Policy, 29(2), 411-424.
Flores, A. M. M. (2017). Innovation Journalism: a multiple concept. Brazilian Journalism Research, 13(2), 156-179.

Gil, A. C. (2002). Como Elaborar Projetos de Pesquisa. São Paulo: Atlas.

Godoy, A. S. (1995). Introdução à pesquisa qualitativa e suas possibilidades. Revista de administração de empresas, 35, 57-63.

Jacomossi, R. R., \& Demajorovic, J. (2017). Fatores determinantes da aprendizagem organizacional para a inovação ambiental: um estudo multicaso. $R A C$ Revista de Administração Contemporânea, 21(5).

Juliani, M. P., Sczymczak, M., do Amarante, M. V., \& de Guimarães, J. C. F. (2015). Ações e resoluções para uma empresa em franca expansão na área de educação superior: Caso de Ensino. Revista Brasileira de Ensino Superior, 1(2), 42-53.

Karam, D. J. (2006). Modelo de negócio para mobilidade e interatividade em ambientes convergentes heterogêneos. Tese de Doutorado, Universidade de São Paulo, São Paulo.

Keupp, M. M., Palmié, M., \& Gassmann, O. (2012). The strategic management of innovation: A systematic review and paths for future research. International Journal of Management Reviews, 14(4), 367-390.

Magretta, J. (2002). Why business models matter. Harvard Business Review, 80:86-92.

Matias-Pereira, J., \& Kruglianskas, I. (2005). Gestão de inovação: a lei de inovação tecnológica como ferramenta de apoio às políticas industrial e tecnológica do Brasil. RAE-eletrônica, 4(2).

Osterwalder, A., \& Pigneur, Y. (2013). Business model generation: inovação em modelos de negócios. Rio de Janeiro: Alta Books Editora.

Manual de Oslo (1997). Diretrizes para coleta $e$ interpretação de dados sobre inovação, 149-151 (3a ed., Tradução sobre responsabilidade de Financiadora de Estudos e Projetos - FIBEP). Recuperado em 26 março, 2018, de http://www.mctic.gov.br/mctic/export/sites/instituci onal/indicadores/detalhe/Manuais/OCDE-Manualde-Oslo-3-edicao-em-portugues.pdf

Palombo, L. F. D. R. (2006). Processos de gestão da inovação na Sociedade em Rede: Uma abordagem em Engenharia Ontológica. Dissertação de Mestrado, Pontifícia Universidade Católica do Paraná, Curitiba. 
Renault, T. B., de Araujo Fonseca, M. V., Cunha, R. M., \& da Silva Carvalho, R. (2011). Empreendedorismo acadêmico na COPPE/UFRJ: reflexões sobre empresas criadas com a participação de professores. Revista Organizações em Contexto, 7(14), 1-28.

Rodrigues, L. C., Silveira, A., Kono, C. M., \& Lenzi, F. C. (2013). Inovação e Modelo de Negócio-Um estudo de caso no setor vitivinicultor. Revista Ibero-Americana de Estratégia, 12(2), 250.

Soto Rojas, E. P. (2014). Elementos de suporte à elaboração de modelos de negócios para rede de empresas. Tese de Doutorado, Universidade Estadual de Campinas, São Paulo.

Takeuchi, H. \& Nonaka, I. (2008). Gestão do conhecimento. Porto Alegre: Bookman.

Tidd, J. \& Bessant, J. R. (2015). Gestão da inovação. Porto Alegre: Bookman.

Trierveiler, H. J. (2015). Orientações para a aplicação do conhecimento organizacional no contexto de iniciativas de inovação no modelo de negócio.
Dissertação de Mestrado, Universidade Federal de Santa Catarina, Florianópolis.

Trierveiler, H. J., Sell, D., \& dos Santos Pacheco, R. C. (2015). A importância do conhecimento organizacional para o processo de inovação no modelo de negócio. Navus-Revista de Gestão $e$ Tecnologia, 5(1), 113-126.

Tschumi, H. D. S. (2015). Fluxo do conhecimento sobre plantas medicinais em uma rede de atores da Grande Florianópolis. Dissertação de Mestrado, Universidade Federal de Santa Catarina, Florianópolis.

Turri, S. N. Z. \& Abreu Jr, O. F. de. (2015). Transformações na indústria fonográfica no Brasil: mudanças no modelo de negócio pelo uso da internet. RAD, 17, 86-117.

Vaccaro, G. L. R., \& Mendes, C. A. (2011). O Processo de Inovação em Tríplice Hélice: uma Análise de Casos da Coréia do Sul. Anais do $8^{\circ}$ Congresso Brasileiro de Gestão de Desenvolvimento de Produto-CBGDP, Porto Alegre, RS, Brasil. 